\title{
Graphene-Gold Nanoparticles Nanohybrids for Electrochemical Detection of Malachite Green
}

\author{
Xiu-Chun Guo ${ }^{1, \dagger^{*},}$, Xuan $\mathrm{Cao}^{2,{ }^{\dagger}}$, Hai-Hui Wang ${ }^{3}$, Meng Yuan ${ }^{3}$, Xuan-Jie Chen ${ }^{1}$, Wen-Yi Kang ${ }^{1}$, \\ Wen-Hui Zhou ${ }^{3, * *}$ \\ ${ }^{1}$ Institute of Chinese Materia Medica, Henan University, Kaifeng 475004, China. \\ ${ }^{2}$ Institute of Oceanographic Instrumentation, Shandong Academy of Sciences, Qingdao 266061, \\ China. \\ ${ }^{3}$ the Key Laboratory for Special Functional Materials of MOE, Henan University, Kaifeng 475004, \\ China. \\ *E-mail: guoxiuchun@henu.edu.cn \\ **E-mail: zhouwh@ @enu.edu.cn, zhouwh@ foxmail.com \\ $\uparrow$ These two authors contributed equally to this work.
}

doi: $10.20964 / 2017.08 .49$

Received: 27 April 2017 / Accepted: 8 June 2017 / Published: 12 July 2017

Malachite green (MG) was an important bactericide and is now banned in different countries due to it's bad effect to human health. In this work, graphene-gold nanohybrids (Graphene-GNPs) were prepared by the chemical co-reduction of Au (III) and graphene oxide (GO) with sodium citrate. These Graphene-GNPs were characterized by TEM, SEM, XRD and EDS. After deposition on glassy carbon electrode (GCE), an electrochemical sensor was proposed for the electrochemical detection of MG. The electrocatalytic oxidation of MG on Graphene-GNPs modified GCE (Graphene-GNPs/GCE) was investigated by differential pulse voltammetry (DPV), cyclic voltammetry (CV) and electrochemical impedance spectroscopy (EIS). The results showed that the Graphene-GNPs could enhance the electrochemical detection performance towards oxidation of MG. Under the optimized condition, the constructed MG electrochemical sensor showed linear dynamic range from $0.1 \mu \mathrm{m}$ to $800 \mu \mathrm{M}$. Moreover, the proposed MG electrochemical sensor has also been successfully used for MG determination in real water samples with satisfied recoveries $(97.5 \%$ to $109.6 \%$ ) and precision $(0.35 \%$ to $5.57 \%)$.

Keywords: Malachite green; MG; Graphene-Gold nanoparticles nanohybrids; Electrochemical detection; electrochemical sensor.

\section{FULL TEXT}


(C) 2017 The Authors. Published by ESG (www.electrochemsci.org). This article is an open access article distributed under the terms and conditions of the Creative Commons Attribution license (http://creativecommons.org/licenses/by/4.0/). 